\title{
COMPARATIVE STUDY OF ACL RECONSTRUCTION WITH ANATOMICAL POSITIONING OF THE TUNNELS USING THE PATELLAR TENDON VERSUS HAMSTRING TENDON
}

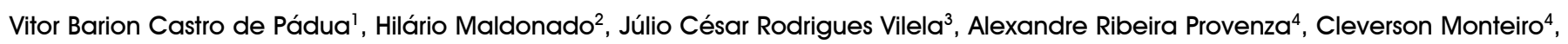
Heleno Cavalcante de Oliveira Neto ${ }^{4}$

\section{ABSTRACT}

Objective: To compare ACL reconstruction with anatomical positioning of the tunnels using the hamstring or patellar tendons. Methods: We prospectively evaluated 52 patients who underwent ACL reconstruction using the Chambat's technique, with anatomical positioning of the tunnels drilled outside in. They were divided into group A, with 27 patients, using the patellar tendon as a graft, and group B, with 25 patients, using the hamstring. Results: In group A 26 patients were very satisfied or satisfied and 1 unhappy, in group B. 25 patients were very satisfied or satisfied with the procedure $(p=0.990)$. According to the Lysholm scale, group A had a mean score of 96.11 and group $B, 95.32(p=0.594)$. In relation to preoperative IKDC, $100 \%$ of the patients in group A and $92 \%$ of those in group B were IKDC C or D $(\mathrm{p}=0.221)$; in the assess- ment with a minimum of two-year follow-up, $96 \%$ of group A and $92 \%$ of group B were IKDC A or B $(p=0.256)$. The Lachman test, pivot shift, return to sports activities, and the comparative difference in anterior translation (Rolime$\operatorname{ter}^{\mathrm{TM}}$ ) also showed no statistically significant difference. In group A, 5 patients $(18.5 \%)$ were unable to kneel on a hard surface, whereas no patient in group B had this complaint. Conclusion: The anterior cruciate ligament reconstruction presents similar results using the hamstring or patellar tendon with anatomical positioning of the tunnels. Drilling the femoral tunnel outside in is a reproducible and accurate option in the correct placement the femoral tunnel.

Keywords - Anterior Cruciate Ligament; Patellar Ligament; Knee/anatomy \& histology

\section{INTRODUCTION}

Anterior cruciate ligament (ACL) injuries are common in athletes, incapacitating for certain sports activities and predispose towards meniscal and cartilage lesions that may evolve to arthrosis ${ }^{(1)}$.

Since the studies by Clancy and Dejour, in the $1980 \mathrm{~s}^{(2,3)}$, and with the development of arthroscopic techniques, there has been great evolution in ACL treatments.

ACL reconstruction leads to excellent results, enabling a return to sports activities, but the problem of rotational instability has still not been solved ${ }^{(4)}$.
The patellar tendon was the graft material that was considered to be the gold standard for ACL reconstruction over the last decade ${ }^{(5,6)}$. This tendon and the flexor tendons are currently the graft materials that are used most ${ }^{(7,8)}$, and each has its advantages and disadvantages $^{(9,10)}$.

Over recent years, reconstructions with double bands have been studied in an attempt to resolve the issue of rotational instability, but this has still not been achieved. However, the great contribution made by these studies has been in relation to the attention given to the anatomy of the ACL and the need for correct positioning of the tunnels ${ }^{(11)}$, considering that the big-

1 - Lecturer in Orthopedics at the School of Medicine, University of Marília (UNIMAR), Marília, SP, Brazil.

2 -Titular Professor of Orthopedics and Traumatology, Marília Medical School (FAMEMA), Marília, SP, Brazil.

3 -Physician in the Clinical Staff at Marília University Hospital, Marília, SP, Brazil.

4 -Third-year Residents in the Orthopedics Service, Santa Casa de Misericórdia de Marília, Marília, SP, Brazil.

Work performed at the Prof. Dr. Hilário Maldonado Orthopedics Clinic and Marília University Hospital, Marília, SP.

Correspondence: Vitor Barion Castro de Pádua, Av. das Esmeraldas 3023, 17516-000 Marília, SP. E-mail: vtrpadua@yahoo.com.br

Received for publication: 11/23/2010, accepted for publication: 11/07/2011 
gest cause of failure in ACL reconstruction is technical failure, mainly with regard to tunnel positioning. This occurs especially with the femoral tunnel and usually consists of positioning that is too anterior ${ }^{(12)}$.

According to the anatomy of the ACL, its origin is completely on the axial face of the lateral condyle, in its most proximal and posterior portion, below the lateral intercondylar crest ${ }^{(13)}$.

The objective of this study was to compare ACL reconstructions with anatomical positioning of the tunnels, between using quadruple flexor tendons and using the patellar tendon.

\section{MATERIALS AND METHODS}

Between January 2007 and June 2008, 76 patients underwent ACL reconstruction according to the Chambat technique, with anatomical positioning of the tunnels, which were both constructed independently and from outside to inside. A quadruple flexor tendon or patellar tendon graft was used, and all the procedures were performed by the same surgeon. Patients presenting associated peripheral lesions, those with iterative lesions undergoing revision and those with bilateral lesions were excluded. In addition, contact with some patients was lost, and thus 52 patients remained for prospective evaluation. These were divided in group A, consisting of 27 patients who received the patellar tendon as the graft, and group B, consisting of 25 patients who received the flexor tendon.

Group A comprised one female patient and 26 male patients, while group B comprised seven female patients and 18 male patients $(\mathrm{p}=0.022)$. The mean age was 31 years (range: 18-43) in group A and 34 years (range: $21-50$ ) in group B. The meantime that elapsed between the injury and the surgery was 23 months (range: 1 to 120) in group A and 20 months (range: 2 to 160) in group B (Table 1). All the patients presented ACL lesions that were confirmed by magnetic resonance imaging and by physical examination (Lachman and pivot shift), and

Table 1 - Patient distribution in the groups.

\begin{tabular}{l|c|c|c}
\hline & Group A & Group B & \multirow{2}{*}{$\mathbf{p}$} \\
\cline { 2 - 3 } & $\mathbf{P T}^{*}$ & $\mathbf{F T}^{\star \star}$ & \\
\hline Number of patients & 27 & 25 & \\
\hline Sex (Male/Female) & $26 / 1$ & $18 / 7$ & $\mathrm{p}=0.022$ \\
\hline Age & $31(18-43)$ & $34(21-50)$ & \\
\hline $\begin{array}{c}\text { Time elapsed between injury } \\
\text { and surgery (months) }\end{array}$ & $23(1-120)$ & $20(2-160)$ & \\
$\begin{array}{l}\text { *PT: patellar tendon } \\
\text { ** FT: flexor tendons }\end{array}$ & & & \\
\hline
\end{tabular}

they were reevaluated with a minimum follow-up of two years (range: $2-3.5$ years). With regard to the trauma mechanism, 23 patients $(85.1 \%)$ in group A and $18(72.0 \%)$ in group B had suffered their injury through playing soccer (Table 2).

Table 2 - Injuries according to type of sport practiced.

\begin{tabular}{c|c|c|c|c}
\hline \multirow{2}{*}{ Sport } & \multicolumn{2}{|c|}{ Group A } & \multicolumn{2}{c}{ Group B } \\
\cline { 2 - 5 } & $\mathrm{n}$ & $\%$ & $\mathrm{n}$ & $\%$ \\
\hline Soccer & 23 & 85.18 & 18 & 72.00 \\
\hline Jiu-Jitsu & 3 & 11.11 & & \\
\hline Basketball & 1 & 3.70 & & \\
\hline Moto & & & 2 & 8.00 \\
\hline Volleyball & & & 2 & 8.00 \\
\hline Running & & & 2 & 8.00 \\
\hline Taekwondo & & & 1 & 4.00 \\
\hline Total & 27 & & 25 & \\
\hline
\end{tabular}

\section{SURGICAL TECHNIQUE}

The reconstruction was done using the Chambat technique $^{(14)}$ for the patellar tendon. By means of an anterior incision above the patellar tendon, its central third (of $1 \mathrm{~cm}$ in thickness) was harvested together with a block of patellar bone of 9 X $20 \mathrm{~mm}$ and another from the tibia of trapezoidal shape, measuring 11 X $25 \mathrm{~mm}$ (Figure 1).

After performing arthroscopy and treatment of associated lesions, the tunnels were constructed independently and from outside to inside, starting from the femur and using the Chambat (Phusis) femoral guide. This was brought in through the anteromedial portal and was attached to the most proximal edge of the axial face of the lateral condyle. By means of a $1.5 \mathrm{~cm}$ lateral access above the lateral epicondyle, the guidewire was introduced from outside to inside. It emerged intra-articularly, perpendicular to the axial face of the lateral condyle, at the anatomical location of the ACL on the femur.

By means of this guidewire, the initial hole was drilled was outside to inside, using a $6 \mathrm{~mm}$ cannulated bit, and this was progressively enlarged to a size of $10 \mathrm{~mm}$ (Figure 2).

The tibial tunnel was constructed using a Chambat (Phusis) tibial guide, taking the remains of the ACL on the tibia as a reference point, with progressive drilling out to the size of $9 \mathrm{~mm}$. The graft was introduced from proximal to distal, and was inverted, i.e. the smaller patellar baguette that was introduced first with the aid of a Kelly was destined for the tibial tun- 


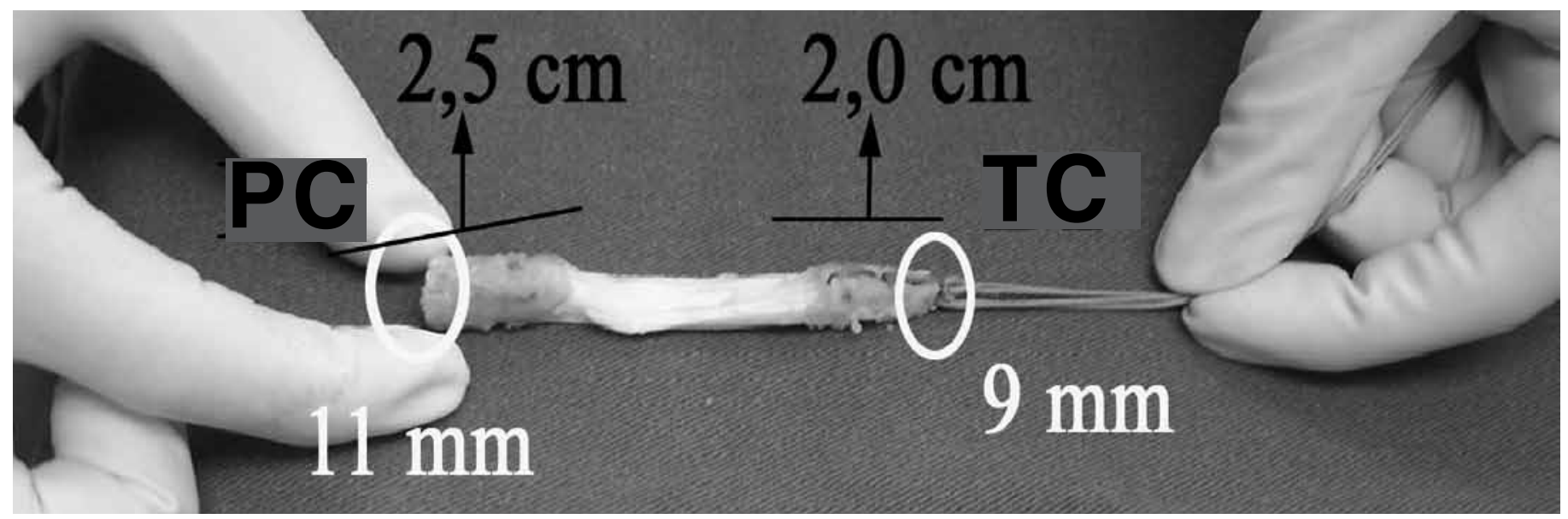

Figure 1 - Graft from patellar tendon: patellar cylinder (BP) and tibial cylinder (BT).

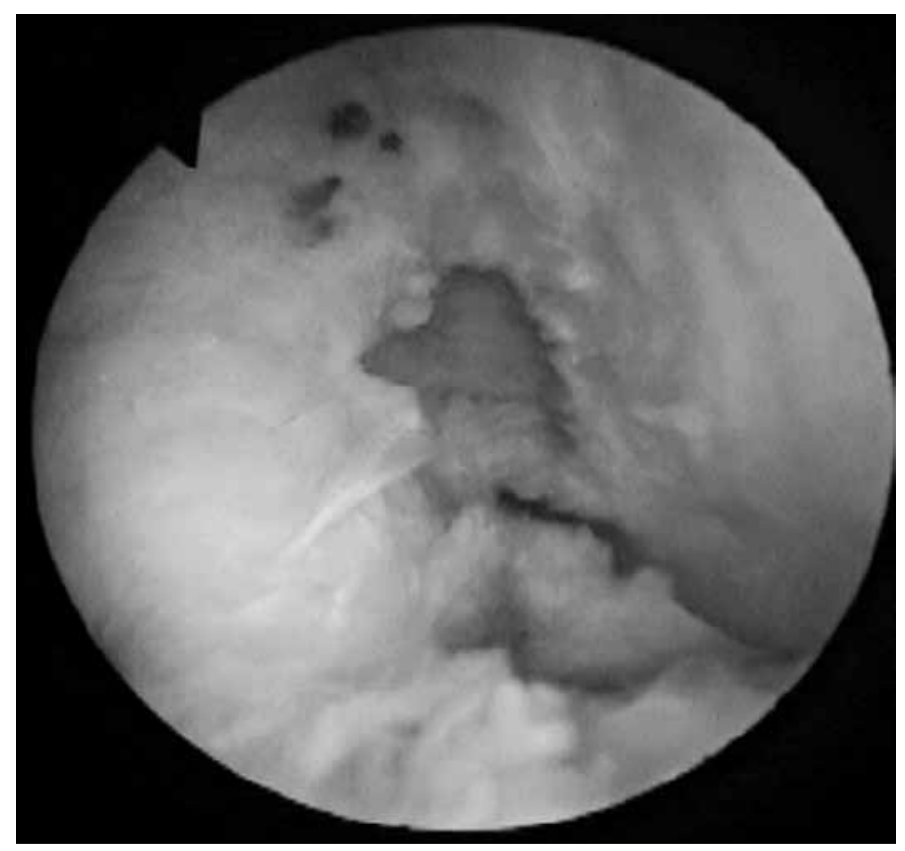

Figure 2 - Femoral tunnel at anatomical location.

nel, and the trapezoidal tibial baguette was destined for the femoral tunnel.

While the patellar baguette was being pulled through the tibial tunnel, the trapezoidal tibial baguette was attached to the femur, from outside to inside in "press fit" form. Following this, tibial fixation was performed at 30 degrees of flexion, using an interference screw.

In the case of the flexor tendons, the tunnels were made in the same manner and with the same guides, up to a size of $8 \mathrm{~mm}$ or $9 \mathrm{~mm}$, depending on the size of the quadruple graft from the flexor tendons. These were harvested by means of a small access above their tibial insertion, which was preserved (Figure 3).

The prepared graft was introduced from distal to

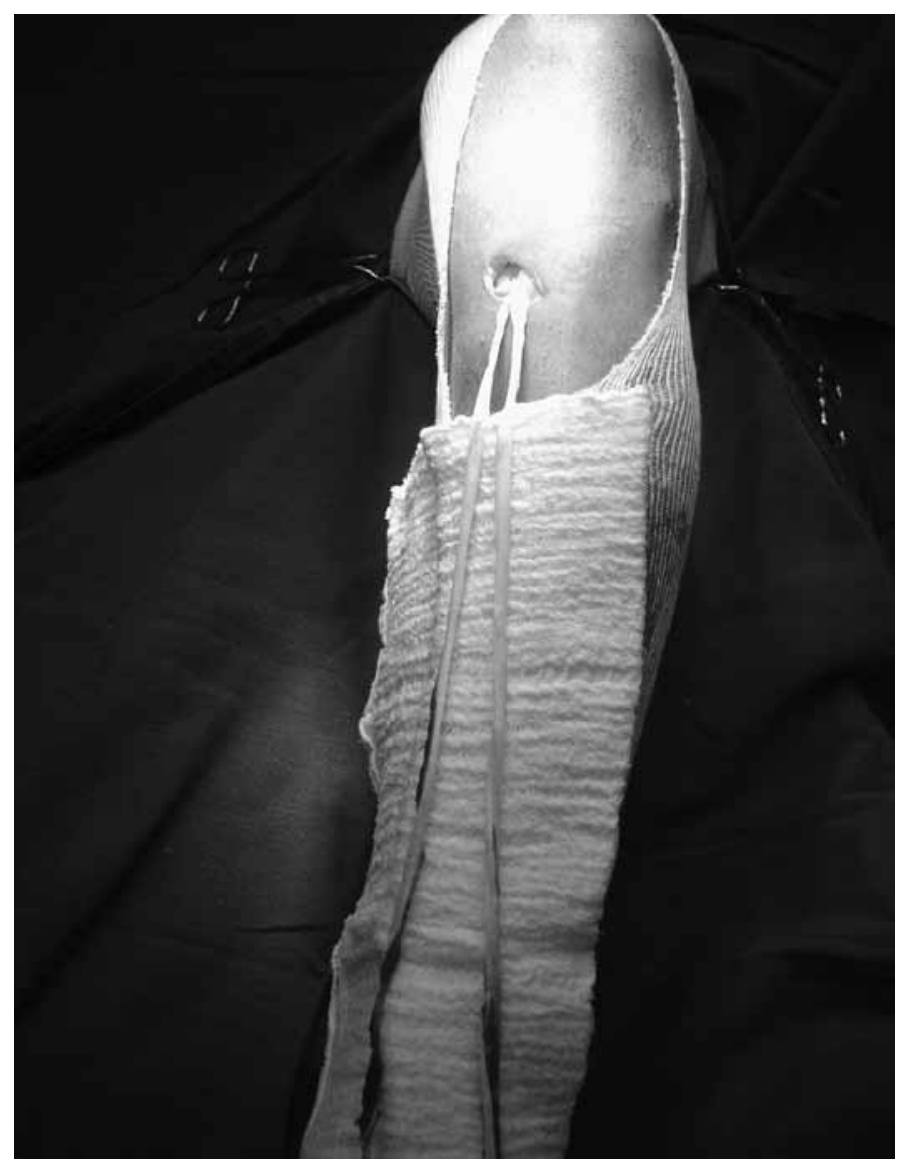

Figure 3 - Flexor tendons with tibial insertion maintained.

proximal, and was fixed using a first interference screw in the tibia, which thus generated a double fixation, since the tibial insertion was maintained. Following this, it was introduced from outside to inside at 30 degrees of flexion for fixation in the femur, also using an interference screw.

No suction drain was used. The patients were discharged on the following day. Rehabilitation was conducted similarly in the two groups, starting after hos- 
pital discharge, with crutches and progressive partial weight-bearing for two weeks, achieving full range of motion after four weeks. They returned to day-to-day activities between the $4^{\text {th }}$ and $12^{\text {th }}$ weeks and started to run again, with proprioception. They returned to their activities six months after the operation.

\section{Postoperative evaluation}

The patients included in this study were evaluated after a minimum follow-up of two years. The range of motion, Lachman test (hard, delayed hard or soft) and pivot shift (negative,,+++ , or +++ ) were assessed. The comparative differential anterior translation was measured by means of a Rolimeter ${ }^{\mathrm{TM}}$ (Aircast ${ }^{\circledR}$ ). For the functional evaluation, the IKDC index, Lysholm scale, return to sports activities and patient satisfaction were used.

\section{Data analysis}

The results relating to qualitative variables were summarized by means of tables, absolute frequencies and percentages. Those relating to numerical variables were summarized by means of tables, means and standard deviations, minimum values and maximum values. Comparison between the patellar tendon technique (A) and the flexor tendon technique (B), according to the Rolimeter ${ }^{\mathrm{TM}}$ or Lysholm scale, was done by means of Student's t test for independent samples. Associations shown by techniques A and B with the variables of sex, pivot shift, Lachman, return to activities, satisfaction and knee mobility were evaluated by means of Fisher's exact test. Associations shown by techniques $\mathrm{A}$ and $\mathrm{B}$ with meniscal lesions were investigated by means of the chi-square test, and with the IKDC by means of the G test. The level of $5 \%$ probability for rejection of the nullity hypothesis was used ${ }^{(15)}$.

\section{RESULTS}

Seven medial meniscal lesions, five lateral meniscal lesions and three lesions in both menisci were found in group A, while in group B there were six medial meniscal lesions and five lateral meniscal lesions. Sutures were made in one medial meniscal lesion and one lateral meniscal lesion in group $\mathrm{A}$, and three medial meniscal lesions in group $B(p=0.609)$ (Table 3).

Regarding the range of motion, two patients (7.4\%) in group A presented a deficit of less than $5^{\circ}$ of extension. In group B, two patients $(8.0 \%)$ presented a deficit of more than $5^{\circ}$ of flexion, and one of them also presented a deficit of more than $5^{\circ}$ of extension $(p=0.990)$.

In group A, two patients $(7.4 \%)$ presented a delayed hard result in the Lachman test and pivot shift + , while in group B there were six patients $(24.0 \%)$ with delayed hard Lachman $(p=0.134)$ and four $(16,0 \%)$ with pivot shift + , without any statistically significant difference (Table 4).

According to the Lysholm scale, group A attained a mean of 96.11 (SD 4.44; minimum 82) in the final evaluation, and group B attained a mean of 95.32 (SD 6.12; minimum 72) $(\mathrm{p}=0.594)$.

The preoperative IKDC index showed that $100 \%$ of the patients in group A and $92 \%$ in group B were IKDC C or D $(p=0.221)$. In the postoperative evaluation after at least two years of follow-up, $96 \%$ of group A and $92 \%$ of group B were IKDC A or B (p = 0.256 ) (Table 5), which was not statistically different.

The comparative differential in anterior translation according to the Rolimeter ${ }^{\mathrm{TM}}$ (Aircast $\mathrm{R}$ ) was $5.8 \mathrm{~mm}$ (range: 4-7) in group A and $6.2 \mathrm{~mm}$ (range: 4-9) in group B before the operation. This evolved to 0.81

Table 3 - Meniscal lesions.

\begin{tabular}{c|c|c|c|c|c|c|c|c|c|c|c}
\hline & \multicolumn{2}{|c|}{ Medial } & \multicolumn{2}{|c|}{ Lateral } & \multicolumn{2}{c|}{$\begin{array}{c}\text { Medial and } \\
\text { Lateral }\end{array}$} & \multicolumn{2}{|c|}{$\begin{array}{c}\text { Medial } \\
\text { suture }\end{array}$} & \multicolumn{2}{|c|}{$\begin{array}{c}\text { Lateral } \\
\text { suture }\end{array}$} & \multirow{2}{*}{ p } \\
\cline { 2 - 10 } & $\mathrm{n}$ & $\%$ & $\mathrm{n}$ & $\%$ & $\mathrm{n}$ & $\%$ & $\mathrm{n}$ & $\%$ & $\mathrm{n}$ & $\%$ & \\
\hline Group A & 7 & 25.9 & 5 & 18.5 & 3 & 11.1 & 1 & 3.7 & 1 & 3.7 & 0.609 \\
\hline Group B & 6 & 24.0 & 5 & 20.0 & & & 3 & 12.0 & & & \\
\hline
\end{tabular}

Table 4 - Lachman and pivot shift tests after the operation.

\begin{tabular}{c|c|c|c|c|c|c|c}
\hline \multirow{2}{*}{} & \multicolumn{3}{|c|}{ Lachman } & \multicolumn{3}{c}{ Pivot shift } \\
\cline { 2 - 8 } & Hard & $\begin{array}{c}\text { Delayed } \\
\text { hard }\end{array}$ & Soft & 0 & + & ++ & +++ \\
\hline Group A & $25(92.6 \%)$ & $2(7.4 \%)$ & 0 & $25(92.6 \%)$ & $2(7.4 \%)$ & 0 & 0 \\
\hline Group B & $19(76.0 \%)$ & $6(24.0 \%)$ & 0 & $21(84.0 \%)$ & $4(16.0 \%)$ & 0 & 0 \\
\hline & \multicolumn{3}{c|}{$p=0.134$} & \multicolumn{3}{c}{$p=0.592$} \\
\hline
\end{tabular}

Table 5 - International Knee Documentation Committee (IKDC)

\begin{tabular}{c|c|c|c|c}
\hline \multirow{2}{*}{} & \multicolumn{2}{|c|}{ Before operation } & \multicolumn{2}{c}{ After operation } \\
\cline { 2 - 5 } & Group A & Group B & Group A & Group B \\
\hline A & 0 & 0 & $18(66.7 \%)$ & $20(80.0 \%)$ \\
\hline B & 0 & $2(8.0 \%)$ & $8(29.6 \%)$ & $3(12.0 \%)$ \\
\hline C & $19(70.4 \%)$ & $16(64.0 \%)$ & $1(3.7 \%)$ & $2(8.0 \%)$ \\
\hline D & $8(29.6 \%)$ & $7(28.0 \%)$ & 0 & 0 \\
\hline p & 0.221 & & 0.256 & \\
\hline
\end{tabular}


mm (range: $0-3)(\mathrm{p}=0.314)$ and $1.12 \mathrm{~mm}$ (range: $0-4)(p=0.289)$, respectively in groups A and B, also without any statistical difference (Table 6).

In group A, three patients (11.1\%) changed their activities: one with a reduction in level and two with replacement activities. In group $B$, four patients $(16.0 \%)$ changed their activities: three with reductions and one with a replacement activity $(p=0.41)$.

The patients were asked about their degree of satisfaction (very satisfied, satisfied, dissatisfied or very dissatisfied). In the patellar tendon group, 26 (96.3\%) were very satisfied (24) or satisfied (2), while one patient was dissatisfied. In the flexor tendon group, all the patients were either very satisfied (20) or satisfied (5) $(\mathrm{p}=0.99)$ (Table 7).

In group A, three patients (11.1\%) presented complications: one case of neuropraxia of the sciatic nerve from using the tourniquet, which took around one year to recover from; one case of Cyclops syndrome that was operated nine months after the reconstruction; and one patient with anterior pain when running, and this was the dissatisfied patient. One patient in group B $(4.0 \%)$ presented the complication of Sudeck's atrophy, with limitations on extension and flexion.

In relation to graft harvesting, five patients (18.5\%) in the patellar tendon group were unable to kneel on the operated knee, whereas no one in the flexor group presented this type of complaint $(p=0.052)$.

One patient in group A suffered a new rupture two years after the reconstructed, and one patient in group $\mathrm{B}, 18$ months after the surgery. In both cases, a new traumatic episode of spraining occurred.

Drilling of the femoral tunnel from outside to inside reached the anatomical site of the ACL below the lateral intercondylar crest, as confirmed by tomography (Figure 4).

Table 6 - Rolimeter ${ }^{\mathrm{TM}}$ (Aircast $®$ ): comparison before and after the operation.

\begin{tabular}{l|c|c|c|c|c|c|c}
\hline & \multicolumn{3}{|c|}{ Before operation } & \multicolumn{3}{c|}{ After operation } & \multirow{2}{*}{ t test p } \\
\cline { 2 - 7 } & Mean & SD* $^{*}$ & (Min-Max) & Mean & SD* & (Min-Max) & \\
\hline Group A & 5.88 & 0.97 & $(4-7)$ & 0.81 & 0.92 & $(0-3)$ & 0.314 \\
\hline Group B & 6.20 & 1.22 & $(4-9)$ & 1.12 & 1.12 & $(0-4)$ & 0.289 \\
\hline
\end{tabular}

Table 7 - Level of satisfaction.

\begin{tabular}{c|c|c|c|c|c|c|c|c|c}
\hline & \multicolumn{2}{|c|}{$\begin{array}{l}\text { Very satis- } \\
\text { fied }\end{array}$} & \multicolumn{2}{|c|}{ Satisfied } & \multicolumn{2}{|c|}{ Dissatisfied } & \multicolumn{2}{|c|}{$\begin{array}{c}\text { Very dissat- } \\
\text { isfied }\end{array}$} & \multirow{2}{*}{$\mathbf{p}$} \\
\cline { 2 - 8 } & $\mathbf{n}$ & $\%$ & $\mathbf{N}$ & $\%$ & $\mathbf{n}$ & $\%$ & $\mathbf{n}$ & $\%$ & \\
\hline Group A & 24 & 88.9 & 2 & 7.4 & 1 & 3.7 & 0 & - & $p=0.999$ \\
\hline Group B & 20 & 80.0 & 5 & 20.0 & 0 & - & 0 & - & \\
\hline
\end{tabular}
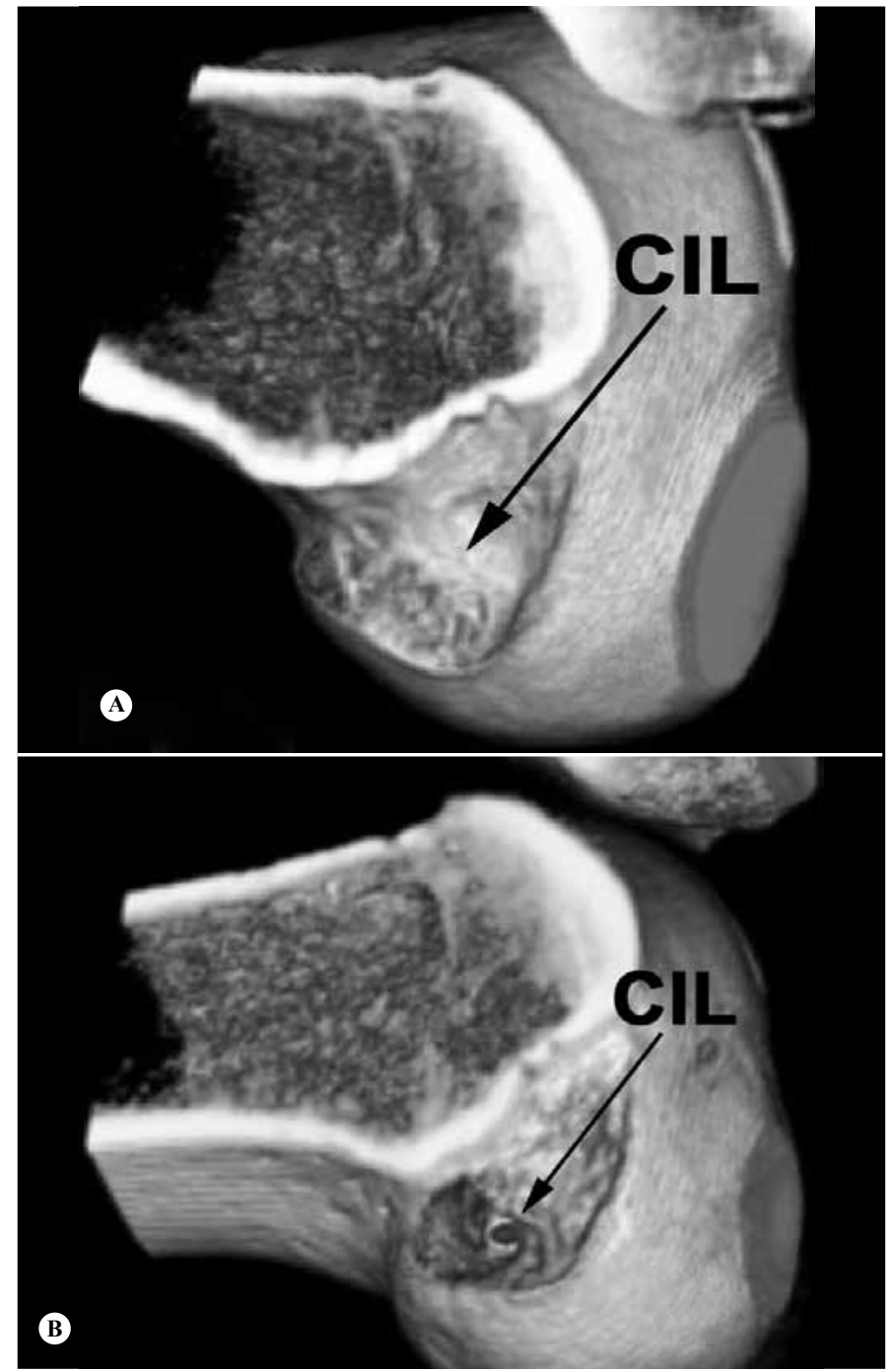

Figure 4 - Computed tomography scan showing the location of the femoral tunnel, posterior to the lateral intercondylar crest. (A) Before the operation. (B) After the operation.

\section{DISCUSSION}

Over the last two decades, ACL reconstruction using the patellar tendon has been considered to be the gold standard $^{(6)}$. However, because of morbidity caused by graft harvesting, there has been increasing use of the flexor tendons, which has given rise to a series of comparative studies between the two types of graft $^{(16-18)}$.

Some authors have reported that there is a slight stability advantage in using the patellar tendon rather than the flexor tendons ${ }^{(19)}$. However, a meta-analysis by Biau et $\mathrm{al}^{(9)}$ did not find any evidence that one technique was superior to the other. It only found that harvesting the patellar tendon led to greater morbidity.

Some studies have shown that using the flexor tendons produced cases of slackness, in comparison with using the patellar tendon, because of the fixation 
methods ${ }^{(8,20)}$. Evolution of these cases made the results similar. In another meta-analysis, Podromos et $\mathrm{al}^{(21)}$ confirmed that the superiority of the patellar tendon was due to failure of flexor tendon fixation, and that using suspended fixation led to the best results.

In our study, to attain secure fixation with the flexor tendons, we maintained the distal insertion in the tibia by means of an interference screw, thus leading to double tibial fixation. In the femur, because of the anatomical position of the tunnel (constructed from outside to inside), the graft made a curve of almost $90^{\circ}$, thereby diminishing the traction force. In the cases with the patellar tendon, femoral fixation was achieved by means of the "press fit" technique: not only is this biological and safe ${ }^{(22,23)}$, but also it avoids screw deviation or breakage of the posterior cortical boner ${ }^{(17)}$.

Although some authors have reported that patients have returned to a higher activity level with the patellar tendon $^{(24)}$, Pinczewski ${ }^{(25)}$ did not find any difference in results between the two types of graft, in series with ten years of follow-up. However, because of the lower morbidity from harvesting the flexor tendons, and because of the fewer radiographic abnormalities found in this group, these tendons were indicated as the first choice. This was in agreement with Prodromos ${ }^{(7)}$, who considered that ACL reconstruction using the flexor tendons was the current gold standard.

Our study did not show any significant difference in comparisons of ACL reconstruction between using the patellar tendon and using the flexor tendons, according to the pivot shift, Lachman, IKDC, Lysholm, return-to-activity and patient satisfaction scales. Although our study was not randomized or homogenous, its findings were in agreement with previous studies $^{(8,18,25,26)}$.

Persistent anterior pain has been considered by some authors to be a consequence of harvesting the patellar tendon ${ }^{(8,19,27)}$. However, we only found one patient in the patellar tendon group who presented this complaint, which was not significant. We agree with Shelbourne $^{(6)}$ that the loss of full extension might be the cause of the anterior pain, since our patient presented an extension deficit. The morbidity that we found from harvesting the patellar tendon was that five patients $(18.5 \%)$ complained that they were unable to kneel on hard surfaces, whereas none of the patients in group B presented this complaint.

In a study on evidence-based medicine, Spindler ${ }^{(28)}$ found that nine randomized studies comparing the patellar tendon and flexor tendons did not show any significant difference between the groups, except for difficulty in kneeling in the patellar tendon group, thus concluding that the type of graft was not the main determinant of success in the operation.

Today, anatomical reconstruction of the ACL is sought, in an attempt to reproduce its structural and mechanical properties ${ }^{(29)}$. In these attempts to come close to the anatomy and seek better results in relation to rotational instability, double-band ACL reconstruction has been greatly studied ${ }^{(29-31)}$. This appears to be promising, but still lacks results. The greatest contribution of these studies has been the great attention given to the anatomy of the ACL, with raised awareness of the need for correct positioning of the tunnels ${ }^{(11)}$.

Tunnel positioning is more important than the type of graft and fixation, and doing this correctly leads to better results and a lower failure rate ${ }^{(12,32)}$.

Correct positioning in the femur can be attained by means of drilling through the medial accessory por$\mathrm{tal}^{(33)}$ or by drilling from outside to inside, following the Chambat technique ${ }^{(14)}$, which was our choice.

With independent drilling, from outside to inside, we consider that it is easier to achieve correct location in the femur ${ }^{(34,35)}$, below the lateral intercondylar crest $^{(36)}$, without difficulty. This was confirmed by the tomography. In this manner, control over the rotational instability and the final functional result were improved.

Studies comparing ACL reconstruction from outside to inside and from inside to outside have been conducted $^{(37,38)}$, without showing any significant difference. However, $\mathrm{O}^{\prime} \mathrm{Neil}^{(17)}$ found that a greater number of patients with drilling from outside to inside returned to a higher competitive level, and that there was a greater percentage of patients with comparative KT-2000 less than $3 \mathrm{~mm}$.

Drilling from outside to inside has been criticized because of the large lateral incision. However, using the Chambat technique, it is not greater than $2 \mathrm{~cm}$, like in transverse fixation.

Our sample was neither homogenous nor randomized, with a significantly higher percentage of female patients using flexor tendons. This occurred because we initially indicated flexor tendons for women because of the smaller incision and lower sports demands, which thus represents a bias in our study.

We have now changed our approach, and flexor tendons are indicated as the first option, independent of sex and sports activity, with some exceptions like in cases of lesions associated with the medial compartment, in which we prefer to use 
the patellar tendon to avoid greater medial slackness. We agree that independent of the type of graft and fixation, tunnel positioning is the factor leading to the best results ${ }^{(14,18,30,31-34)}$.

\section{CONCLUSION}

ACL reconstruction with anatomical positioning of the tunnels presents similar results using flexor tendons or the patellar tendon as the graft. Independent

\section{REFERENCES}

1. Bray RC, Dandy DJ. Meniscal lesions and chronic anterior cruciate ligamentdeficiency. Meniscal tears occurring before and after reconstruction. J Bone Joint Surg Br. 1989;71(1):128-30.

2. Clancy WG Jr, Nelson DA, Reider B, Narechania RG. Anterior cruciate ligament reconstruction using one-third of the patellar ligament, augmented by extraarticular tendon transfers. J Bone Joint Surg Am. 1982;64(3):352-9.

3. Dejour $\mathrm{H}$. [Results of the treatment of anterior laxity of the knee]. Rev Chir Orthop Reparatrice Appar Mot. 1983;69(4):255-302.

4. Tashman S, Collon D, Anderson K, Kolowich P, Anderst W. Abnormal rotational knee motion during running after anterior cruciate ligament reconstruction. Am J Sports Med. 2004;32(4):975-83.

5. Fu FH, Schulte KR. Anterior cruciate ligament surgery 1996. State of the art? Clin Orthop Relat Res. 1996;(325):19-24.

6. Shelbourne KD, Gray T. Results of anterior cruciate ligament reconstruction based on meniscus and articular cartilage status at the time of surgery. Five- to fifteen-year evaluations. Am J Sports Med. 2000;28(4):446-52.

7. Prodromos CC, Han YS, Keller BL, Bolyard RJ. Stability results of hamstring anterior cruciate ligament reconstruction at 2- to 8-year follow-up. Arthroscopy. 2005;21(2):138-46.

8. Harilainen A, Linko E, Sandelin J. Randomized prospective study of ACL reconstruction with interference screw fixation in patellar tendon autografts versus femoral metal plate suspension and tibial post fixation in hamstring tendon autografts: 5-year clinical and radiological follow-up results. Knee Surg Sports Traumatol Arthrosc. 2006;14(6):517-28.

9. Biau DJ, Tournoux C, Katsahian S, Schranz PJ, Nizard RS. Bone-patellar tendon-bone autografts versus hamstring autografts for reconstruction of anterior cruciate ligament: meta-analysis. BMJ. 2006;332(7548):995-1001.

10. Poolman RW, Abouali JA, Conter HJ, Bhandari M. Overlapping systematic reviews of anterior cruciate ligament reconstruction comparing hamstring autograft with bone-patellar tendon-bone autograft: why are they different? J Bone Joint Surg Am. 2007;89(7):1542-52.

11. Steiner M. Anatomic single-bundle ACL reconstruction. Sports Med Arthrosc. 2009;17(4):247-51.

12. Harner CD, Poehling GG. Double bundle or double trouble? Arthroscopy. 2004;20(10):1013-4.

13. Giron F, Cuomo P, Aglietti P, Bull AM, Amis AA. Femoral attachment of the anterior cruciate ligament. Knee Surg Sports Traumatol Arthrosc. 2006;14(3):250-6.

14. Garofalo R, Mouhsine E, Chambat $P$, Siegrist $O$. Anatomic anterior cruciate ligament reconstruction: the two-incision technique. Knee Surg Sports Traumatol Arthrosc. 2006;14(6):510-6.

15. Armitage P, Berry G. Estadística para la investigación biomédica. 3a.ed. Madrid: Harcourt Brace; 1997.

16. Matsumoto A, Yoshiya S, Muratsu H, Yagi M, Iwasaki $Y$, Kurosaka M, et al. A comparison of bone-patellar tendon-bone and bone-hamstring tendon-bone autografts for anterior cruciate ligament reconstruction. Am J Sports Med. 2006;34(2):213-9.

17. O'Neill DB. Arthroscopically assisted reconstruction of the anterior cruciate ligament. A prospective randomized analysis of three techniques. J Bone Joint Surg Am. 1996;78(6):803-13

18. Shaieb MD, Kan DM, Chang SK, Marumoto JM, Richardson AB. A prospective randomized comparison of patellar tendon versus semitendinosus and gracilis tendon autografts for anterior cruciate ligament reconstruction. Am J Sports Med. 2002;30(2):214-20.

19. Eriksson K, Anderberg P, Hamberg P, Löfgren AC, Bredenberg M, Westman I, et al. A comparison of quadruple semitendinosus and patellar tendon grafts in reconstruction of the anterior cruciate ligament. J Bone Joint Surg Br. 2001;83(3):348-54

20. Milano G, Mulas PD, Ziranu F, Piras S, Manunta A, Fabbriciani C. Comparison drilling of the femoral tunnel, from outside to inside, is a reproducible and precise option for correct positioning of the femoral tunnel.

\section{ACKNOWLEDGEMENT}

To Dr. Sebastião Marcos Ribeiro de Carvalho, of the Extension Project (DPE/FFC), Unesp, Marília, SP, for help with statistics, which was an important collaboration for carrying out this work. between different femoral fixation devices for ACL reconstruction with doubled hamstring tendon graft: a biomechanical analysis. Arthroscopy. 2006;22(6):660-8.

21. Prodromos CC, Joyce BT, Shi K, Keller BL. A meta-analysis of stability after anterior cruciate ligament reconstruction as a function of hamstring versus patellar tendon graft and fixation type. Arthroscopy. 2005;21(10):1202.

22. Silva JLV, Tavares Filho GS, Namba MM, Pereira Filho FA, Barbosa M, Albano $M$, et al: Estudo biomecânico, "in vitro", em ovinos, da fixação femoral do tendão patelar na reconstrução do ACL: comparação entre parafusos metálicos de interferência e a fixação sob pressão com bloco ósseo cônico. Rev Bras Ortop. 2003;38(7):400-9

23. Boszotta $\mathrm{H}$. Arthroscopic reconstruction of anterior cruciate ligament using BTB patellar ligament in the press-fit technique. Surg Technol Int. 2003;11:249-53.

24. Laxdal G, Sernert N, Ejerhed L, Karlsson J, Kartus JT. A prospective comparison of bone-patellar tendon-bone and hamstring tendon grafts for anterior cruciate ligament reconstruction in male patients. Knee Surg Sports Traumatol Arthrosc. 2007;15(2):115-25.

25. Pinczewski LA, Lyman J, Salmon LJ, Russell VJ, Roe J, Linklater J. A 10-year comparison of anterior cruciate ligament reconstructions with hamstring tendon and patellar tendon autograft: a controlled, prospective trial. Am J Sports Med. 2007;35(4):564-74

26. Jansson KA, Linko E, Sandelin J, Harilainen A. A prospective randomized study of patellar versus hamstring tendon autografts for anterior cruciate ligament reconstruction. Am J Sports Med. 2003;31(1):12-8.

27. Yunes M, Richmond JC, Engels EA, Pinczewski LA. Patellar versus hamstring tendons in anterior cruciate ligament reconstruction: A meta-analysis. Arthroscopy. 2001;17(3):248-257.

28. Spindler KP, Kuhn JE, Freedman KB, Matthews CE, Dittus RS, Harrell FE Jr. Anterior cruciate ligament reconstruction autograft choice: bone-tendon-bone versus hamstring: does it really matter? A systematic review. Am J Sports Med. 2004;32(8):1986-95.

29. Zantop T, Diermann N, Schumacher T, Schanz S, Fu FH, Petersen W. Anatomical and nonanatomical double-bundle anterior cruciate ligament reconstruction: importance of femoral tunnel location on knee kinematics. Am J Sports Med. 2008;36(4):678-85.

30. Sonnery-Cottet B, Chambat P. Anatomic double bundle: a new concept inanterior cruciate ligament reconstruction using the quadriceps tendon. Arthroscopy. 2006;22(11):1249.e1-4.

31. Yasuda $\mathrm{K}$, Kondo E, Ichiyama H, Kitamura N, Tanabe $\mathrm{Y}$, Tohyama $\mathrm{H}$, et al. Anatomic reconstruction of the anteromedial and posterolateral bundles of the anterior cruciate ligament using hamstring tendon grafts. Arthroscopy. 2004;20(10):1015-25.

32. Fox JA, Nedeff DD, Bach Jr BR, Spindler KP. Anterior cruciate ligament reconstruction with patellar autograft tendon. Clin Orthop Relat Res. 2002;(402):53-63.

33. Zantop T, Kubo S, Petersen W, Musahl V, Fu FH. Current techniques in anatomic anterior cruciate ligament reconstruction. Arthroscopy. 2007;23(9):938-47.

34. Domit Filho M, Monte APC, Nagai M, Ribeiro MV, Maciel LG. Estudo de posicionamento do enxerto na substituição do ligamento cruzado anterior. Rev Bras Ortop. 2002;37(4):141-50.

35. Khalfayan EE, Sharkey PF, Alexander AH, Bruckner JD, Bynum EB. The relationship between tunnel placement and clinical results after anterior cruciate ligament reconstruction. Am J Sports Med. 1996;24(3):335-41.

36. Ferretti M, Ekdahl M, Shen W, Fu FH.Osseous landmarks of the femoral attachment of the anterior cruciate ligament: an anatomic study. Arthroscopy. 2007;23(11):1218-25.

37. Brandsson S, Faxén E, Eriksson BI, Swärd L, Lundin O, Karlsson J. Reconstruction of the anterior cruciate ligament: comparison of outside-in and all-inside techniques. Br J Sports Med. 1999;33(1):42-5.

38. Reat JF, Lintner DM. One-versus two-incision ACL reconstruction. A prospective, randomized study. Am J Knee Surg. 1997;10(4):198-208. 